\title{
ESTUDO COMPARATIVO DE FLORES CASMÓGAMAS, CLEISTÓGAMAS E DE FRUTOS DE CAMAREA AFFINIS ST.-HIL. (MALPIGHIACEAE) ${ }^{1}$
}

\author{
Maria Candida Henrique Mamede ${ }^{2}$
}

Recebido em 30-03-92. Aceito em 23-03-93

RESUMO: 0 gênero Camarea pertence a tribo Gaudichaudieae caracterizada pela redução no número de elementos do androceu, gineceu parcialmente sincárpico, estilete único e ginobásico e pela ocorrência de flores cleistógamas. Neste trabalho é feito o estudo de Camarea affinis St.Hil. no que se refere à morfologia e á anatomia de flores casmógamas e cleistógamas, assim como de seus respectivos frutos.

Palavras-chave: Malpighiaceae, Camarea, morfologia, anatomia, flores cleistógamas e casmógamas, fruto.

\begin{abstract}
The genus Camarea belongs to the tribe Gaudichaudieae, which is traditionally characterized by a solitary gynobasic style, presence of very reduced cleistogamous flowers, an androecium of 6 staminal elements and carpels only partially united. This paper presents information about the morphology and the anatomy of chamosgamous and cleistogamous flowers and fruits of Camarea affinis St. Hil.
\end{abstract}

Key words: Malpighiaceae, Camarea, morphology, anatomy, chasmogamous and cleistogamous flowers, fruit.

\section{Introdução}

0 gênero Camarea pertence à tribo Gaudichaudieae caracterizada pela redução no número de elementos do androceu, gineceu parcialmente sincárpico, estilete único e ginobásico e pela ocorrência de flores cleistógamas (Jussieu, 1843).

1. Parte da Tese de doutoramento. Depto Botânica. Instituto de Biociências, USP.

2. Instituto de Botâmica, Cx.P. 1005, 01061-970, São Paulo, SP. 
Ritzerow (1908) refere cleistogamia em Malpighiaceae para os gêneros Camarea, Janusia, Aspicarpa e Gaudichaudia. Mais recentemente, Lorenzo (1981) verificou que nas flores cleistógamas de Janusia guaranitica (St. Hil.) Adr. Juss. 0 embrião origina-se apomiticamente, ao contrário do mecanismo de autofecundação descrito por Anderson (1980). Apomixia foi referida também para Thryallis glauca Kuntz (Singh, 1959) e para Peixotoa reticulada Adr. Juss. (Anderson, 1982). Segundo Lorenzo (1981), tais flores não são verdadeiramente cleistogâmicas, devendo ser designadas cleistopartenogenéticas, como havia postulado Ritzerow.

Este trabalho tem como objetivo contribuir para o conhecimento da anatomia e morfologia das flores e frutos de Camarea affinis St. Hil.

\section{Material e Métodos}

Nos estudos anatômicos foram utilizadas técnicas de: diafanização de sépalas, pétalas, androceu e gineceu; e, cortes seriados de flores e frutos (Sass, 1951).

Os estudos de flores e frutos foram realizados com material fixado em álcool etílico $70^{\circ} \mathrm{GL}$ ou FAA50. Foram emblocados botões de flores casmógamas e cleistógamas em vários estágios de desenvolvimento, de flores casmógamas abertas e de frutos originados por dois tipos de flores. Foram obtidos cortes transversais e longitudinais com 10 e $12 \mathrm{~cm}$ de espessura os quais foram corados segundo o processo de tripla-coloração com safranina, verde-firme ("fast-green") e hematoxilina de Heidenhain (Conn et al., 1960) e montados em lâminas permanentes.

\section{Material Examinado:}

Camarea affinis St.-Hil. - Goiás, Alto Paraiso de Goiás, Chapada dos Veadeiros, col. M.C.H. Mamede et al. 24, 19.XI. 1987 (SP).

\section{Resultados e Discussão}

0 cálice é formado de cinco sépalas, unidas apenas na base, quatro biglandulosas e uma eglandulosa. Em seção transversal (Figura 21), a sépala apresenta várias camadas de células na região mediana que diminuem gradativamente em direção aos bordos da mesma. Cada sépala recebe dois feixes vasculares do pedicelo que se ramificam dicotomicamente em várias direçōes. As glândulas do cálice apresentam forma oblonga e em geral são do mesmo tamanho. Em seção longitudinal, apresentam na região distal uma epiderme secretora com células altas e estreitas, dispostas em paliçada, com núcleo grande, conteúdo citoplasmático denso e cutícula espessa, e na região proximidal, a epiderme e 
constituída de células não secretoras, mais largas que altas (Figuras 1-3). 0 restante da glândula é formado por tecido parenquimático não secretor. Cada glândula recebe um traço vascular que se origina de uma ramificação de cada um dos feixes vasculares da sépala (Figuras 4-8) e uma vez dentro da glândula esse feixe se ramifica várias vezes em direção ao ápice (região secretora).

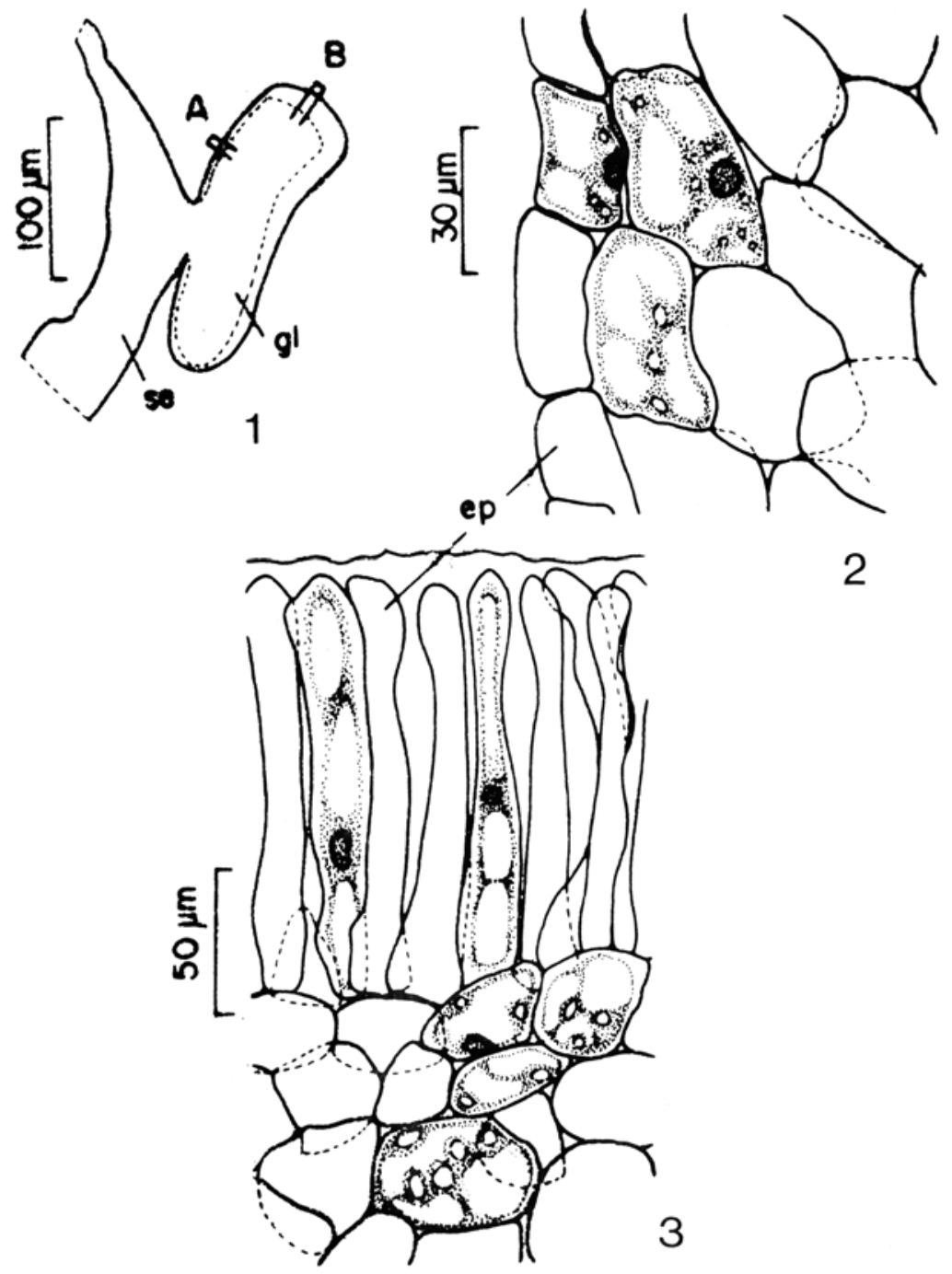

Figuras 1-3. Camarea affinis: 1, diagrama de uma glândula do cálice em seção longitudinal; $2-3$, detalhes da epiderme correspondentes, respectivamente, às regiōes A e B destacadas na Figura 1 (ep= epiderme, gl= glândula, se= sépala). 
As pétalas são mais delgadas que as sépalas e apresentam nervura mediana mais espessa que a lâmina (Figura 21). Cada pétala recebe dois traços vasculares provenientes do pedicelo (Figuras 5-8), os quais se ramificam dicotomicamente e se anastomosam, várias vezes em direção ao ápice da pétala. Os dois feixes, apesar de se ramificarem, permanecem contínuos ao longo da nervura mediana da pétala.

0 androceu é formado por quatro estames e dois estaminódios, cujos filetes apresentam-se adnatos na base (Figuras 10-12), formado um anel quase contínuo interrompido entre o estaminódio oposto a sépala latero anterior (Figura 11, es²) e o estame oposto a sépala latero-posterior (Figura 11, $\mathrm{e}^{2}$ ). Este anel persiste até a altura em que os carpelos apresentam-se livres entre si. Nessa região, o anel divide-se formando dois grupos de elementos (Figura 13). 0 primeiro é formado pelos estames opostos às sépalas látero-posteriores adnatos ao estame oposto à pétala posterior, os quais mantém-se unidos quase até o ápice (Figuras 14-17), separando-se próximo às anteras (Figuras 18,21). 0 segundo grupo compreende os estaminódios oposto às sépalas látero-anteriores adnatos ao estame oposto à sepala anterior (Figuras 13-15), que logo se separam apresentando cada qual seu filete livre (Figuras 16-18).

Os filetes dos estames e estaminódios são irrigados cada um por um feixe vascular que não se ramifica. As anteras são dorsifixas e formadas por duas tecas com deiscência rimosa. Cada teca compreende dois sacos polinicos de tamanhos diferentes, o mais interno menor que o externo (Figura 21). Em seção transversal, os estaminódios apresentam-se preenchidos totalmente por tecido parenquimático com células semelhantes às do parênquima das pétalas (Figura 22).

Os carpelos, em número de três (quatro em $C$. axillaris), apresentam-se unidos entre si apenas na base é unilocular e uniovulado, e recebe um traço vascular que se ramifica para irrigar o óvulo (Figura 4). Os óvulos são anátropos, unitegumentados, com placentação axilar e ligeiramente torcidos (Figura 24). O estilete é único e ginobásico e origina-se apenas do carpelo oposto à sepala anterior (eglandulosa) (Figuras 11-12,20), e é irrigado por três feixes vasculares que não se ramificam (Figuras 12-18). 0 estigma é apical, capitado e papilar.

As flores cleistógamas, bastante reduzidas e localizadas na axila das folhas basais, são em geral solitárias podendo ocorrer duas flores sésseis sustentadas por um pedúnculo comum bastante reduzido (Figuras 19, 23). Apresentam cálice constituido de cinco sépalas eglandulosas, anatomicamente semelhantes às sépalas das flores casmógasmas. $\mathrm{O}$ androceu é formado por um único estame, alterno com as sépalas látero-posteriores, com filete e anteras bastante reduzidos. Os dois carpelos do ovário são livres entre si (Figura 23), uniloculares e uniovulados. Estilete e estigma são ausentes. Foi observada formação de saco embrionário nas flores cleístogamas (Figura 24). Em relação à vascularização. Cada sépala recebe um traço vascular que se ramifica várias vezes dentro da mesma. 0 estame e os dois carpelos recebem, cada um, um feixe vascular e o óvulo é irrigado por uma ramificação originada do traço vascular carpelar (Figura 19). 


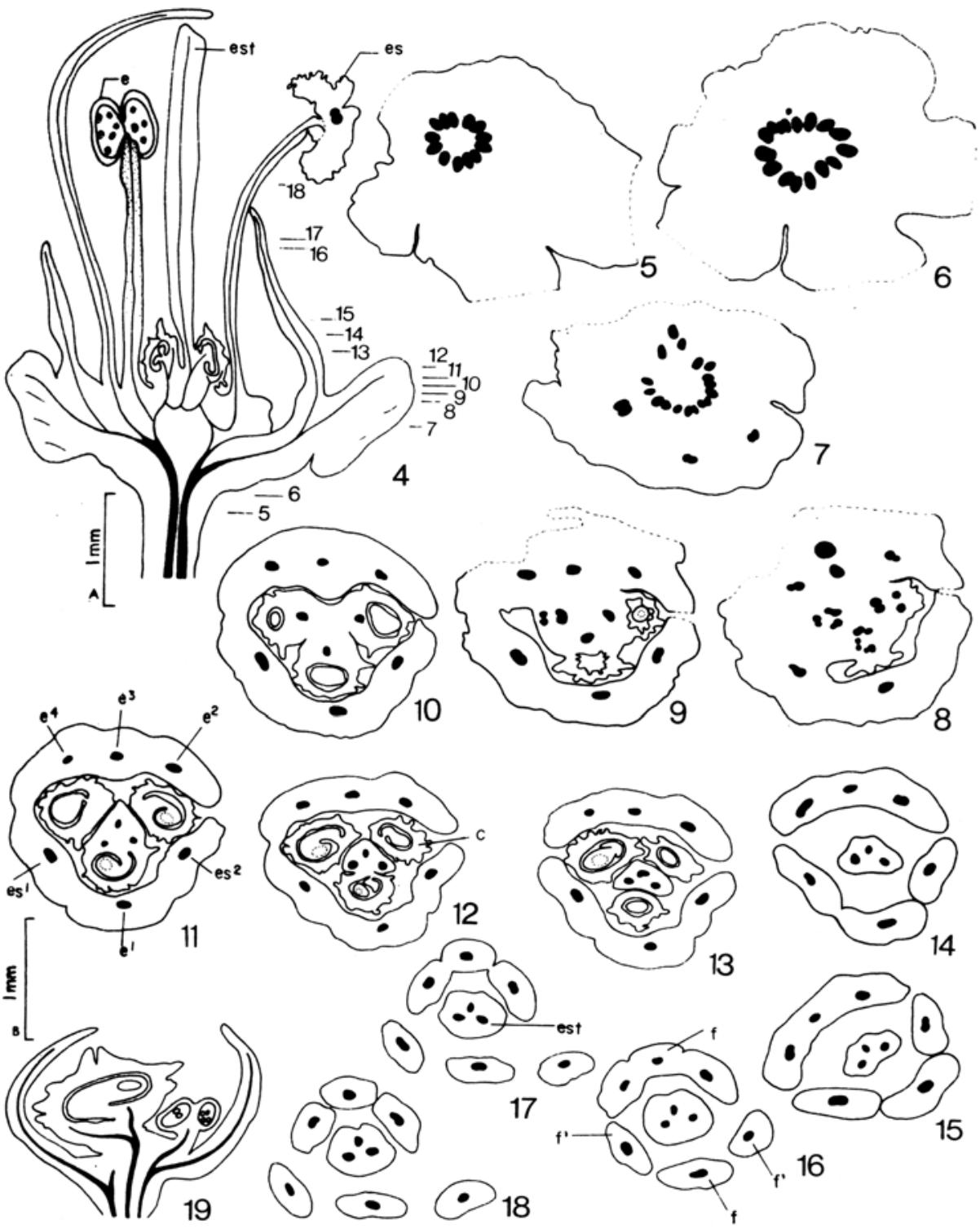

Figuras 4-19: 4-18, representação esquemática de uma flor casmógama de Camarea affinis em corte longitudinal (4) e diagramas dos cortes transversais (5-18) feitos nos diferentes niveis indicados na Figura 4 ( $e=$ estame, es= estaminódio, est= estilete, $\mathrm{f}=$ filete do estame, $\mathrm{f}=$ filete do estaminódio, $\mathrm{e}^{1}$ filete do estame oposto à sépala anterior; $\mathrm{e}$, e $4=$ filete dos estames opostos às sépalas látero posteriores; $\mathrm{e}^{3}=$ filete do estame oposto à pétala posterior; $\mathrm{es}^{1} \mathrm{es}^{2}=$ filete dos estaminódios opostos às sépalas latero-anteriores. 19 , representação esquemática de uma flor cleistógama em seção longitudinal. 

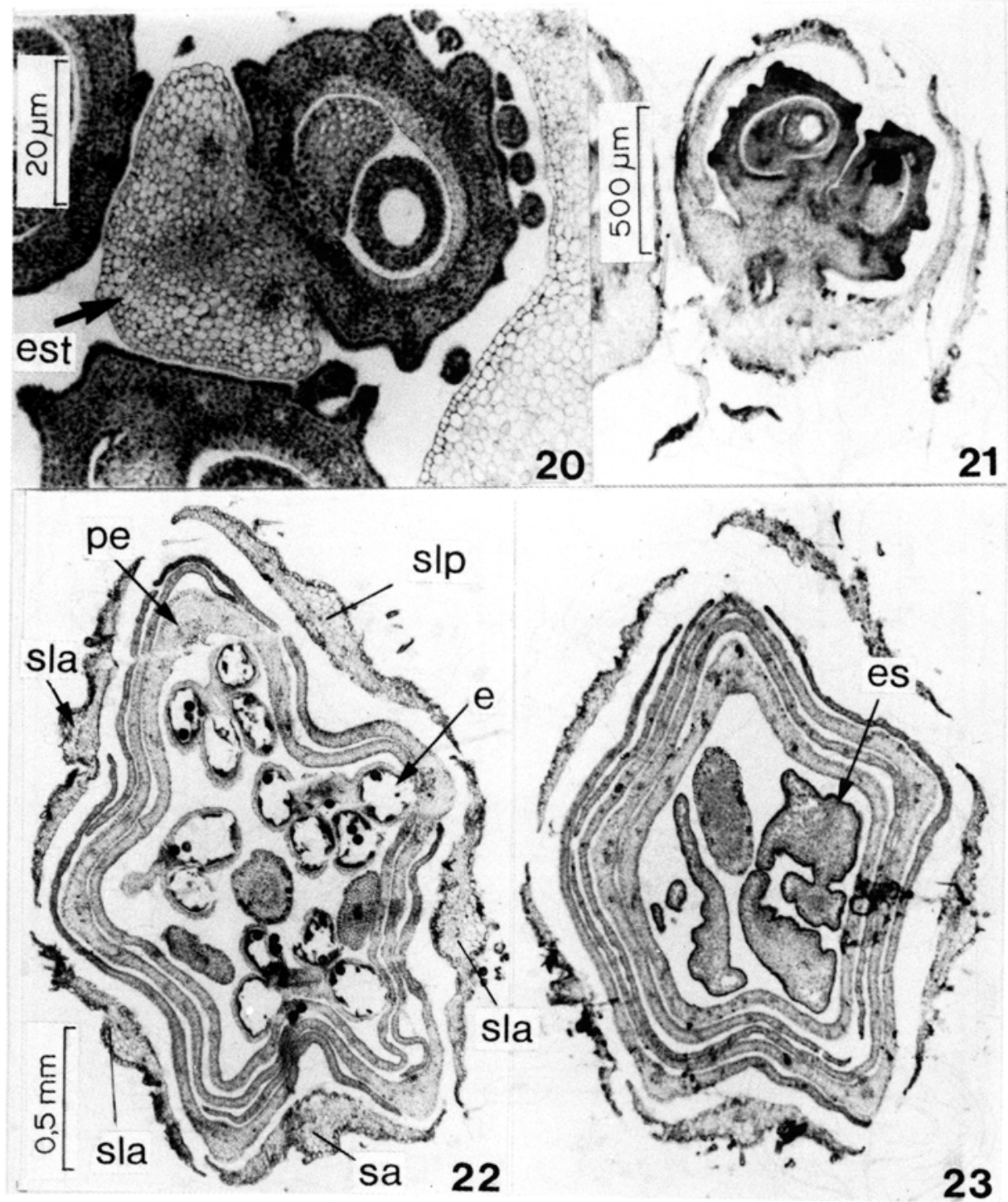

Figura 20-23: 20, diagrama floral esquemático, mostrando a posição dos estames e estaminódios em relação às pétalas e sépalas 21-23, cortes transversais de flores casmógamas de Camarea affinis em niveis diferentes; 21, detalhes do ovário mostrando os carpelos livres e o estilete comunicando-se apenas com o carpelo oposto à sépala anterior e detalhe do androceu na altura dos estames; 23 detalhe do androceu na altura dos estaminódios. Note-se as anteras com lóculos de tamanhos diferentes e os estaminódios constituídos apenas de tecido parenquimático ( $\mathrm{e}=$ estame, es= estaminódio, est= estilete, $\mathrm{sa}=$ sépala anterior; $\mathrm{sl}=$ sépala látero-posterior; $\mathrm{sla}=$ sépala látero-anterior; escalas: $\mathrm{a}=$ Fig. 4; b = Figs. 5-19). 
Tanto as flores casmógamas como as cleistógamas desenvolvem frutos com samarídeos morfologicamente idênticos entre si. Logo após a formação do saco embrionário e fecundação (Figura 24), a parede do ovário apresenta-se formada por uma epiderme com células mais altas que largas e com núcleos grandes (Figura 25). Logo abaixo da epiderme, observa-se um parênquima constituído de 6-7 camadas de células com núcleos grandes, citoplasma pouco denso e fortemente justapostas, sem deixar espaços intercelulares. A camada mais interna, em contato com o tegumento do óvulo, é formada por 3-4 camadas de células alongadas periclinalmente e com núcleos grandes. Entre a camada mais interna e o parênquima podem ser distinguidas de 2-3 camadas de células de natureza meristemática (Figura 25).

No fruto maduro (Figura 26), o endocarpo corresponde à camada mais interna da parede do ovário, apresentando as células mais ou menos degeneradas. 0 mesocarpo é formado por um esclerênquima bastante espesso com 15-20 camadas de células com lúmen reduzido e sem espaços intercelulares. 0 esclerênquima corresponde, provavelmente, à camada meristemática da parede do ovário. 0 epicarpo apresenta 3-4 camadas de células que equivalem ao parênquima e epiderme da parede do ovário (Figura 27).

As glândulas calicíneas de Camarea,bem como de todas as Malpighiaceae, correspodem a elaióforos epiteliais que excretam óleos com alto teor energético, os quais são coletados por abelhas (Centris spp.)e utilizados na alimentação das larvas (Vogel, 1974; Simpson \& Neff, 1981; Hauman-Merck, 1913; Sazima \& Sazima, 1987). Com base na análise anatômica de flores casmógamas de Camarea affinis verificou-se que as glândulas do cálice fazem parte das sépalas, pois o parênquima fundamental das mesmas apresenta continuidade com o parênquima das sépalas. Além disso, o traço vascular que irriga a glândula é ramificação do traço vascular da sépala. Na região distal da glândula, a epiderme apresenta células secretoras. Este padrão não é homogêneo para a família, uma vez que Soares (1979) observou em Bunchosia glandurifera (Jacq.) HBK que as sépalas originam-se do receptáculo floral e apresentam vascularização independente.

As anteras dos estaminódios de Camarea são constituidas de tecido parenquimático não-glandular, não tendo sido observadas papilas ou áreas glandulares nessas estruturas. Gates (1992) refere que os conectivos bastante desenvolvidos de alguns estames de Banisteriopsis campestris (Adr. Jus.) Little apresentam áreas de tecido glandular, cuja secreção talvez atue facilitando a aderência dos grãos de pólen no ventre do inseto durante a polinização.

0 estilete ginobásico das flores casmógamas com comunicação apenas com 0 carpelo oposto a sépala anterior parece ser caracteristico da tribo Gaudichaudieae, uma vez que foi observado também em Janusia guaranitica (Lorenzo, 1981).

As flores reduzidas de Camarea affinis, C. affinis x hirsuta e C. hirsuta podem ser consideradas como cleistógamas verdadeiras ( Lord, 1981), pois apresentam ausência total de corola, redução no tamanho, no número de estames e de carpelos. Jussieu (1943) refere flores cleistógamas em C. affinis, C. hirsuta, C. 

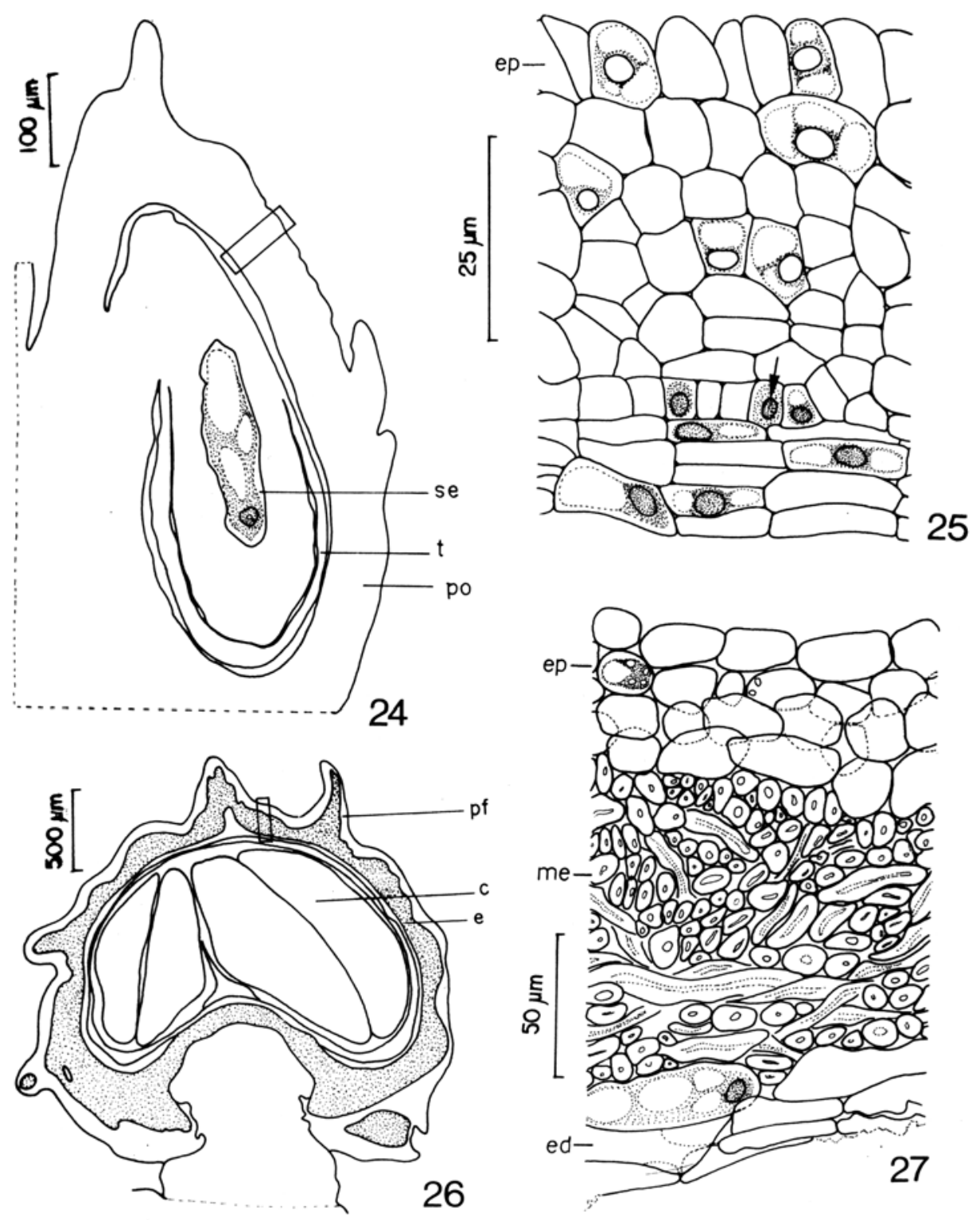

Figura 24-27: 24, flor cleistógama de Camarea affinis: detalhe de duas flores curtamente pediceladas em corte longitudinal (c= carpelo, e= estame); 25-28, Camarea affinis: 25-26, diagrama do ovário (25) e detalhe da parede (27), em corte transversal, de uma flor casmógama, logo após a fecundaçāo, na regiảo indicada em 25; 28-29, diagrama do samarideo (28) e detalhe da parede do fruto (29), em corte transversal da regiảo destacada em 28 ( $c=$ cotilédone, e= esclerênquina, $\mathrm{pf}=$ parede do fruto, $\mathrm{po}=$ parede do ovário, se= saco embrionário, $\mathrm{t}=$ tegumento). 
axillaris e C. ericoides. Através da análise de todo o material disponível foi confirmada cleistogamia para três das espécies supra citadas, não tendo sido observada até o momento para $C$. axillaris. Além disso, em todas essas espécies (incluindo o hibrido) as flores cleistógamas produzem frutos morfologicamente semelhantes aos desenvolvidos de casmógamas, exeto $C$. ericoides na qual não foi observada a ocorrência desse tipo de fruto (Mamede, 1988, 1990a).

Através de estudos anatômicos realizados em flores casmógamas e cleistógamas de Camarea affinis constatou-se que os óvulos de ambas as flores são idênticos, unitegumentados e ligeiramente torcidos muito semelhantes ao óvulo de Janusia guaranitica (Lorenzo, 1981). 0 aparelho oosférico observado no saco embrionário maduro de flores cleistógamas de $C$. affins também apresentouse muito semelhante ao observado em Janusia guaranitica.

Segundo Lord (1981), as flores cleistógamas são formas modificadas de flores casmógamas, adaptadas a autofecundação e representam um mecanismo alternativo de reprodução, o que contradiz idéias anteriores de que flores cleistógamas seriam formas abortivas de flores casmógamas, induzidas unicamente por condiçöes ambientais e sem modificaçōes que assegurassem a autofecundação (Ritzerow, 1908: Uphof, 1938).

Para o gênero Camarea, acredita-se que o mecanismo que controla o desenvolvimento de flores casmógamas é genético, uma vez que nas espécies que apresentam dimorfismo floral, as flores cleistógamas são encontradas em quaisquer individuos independentemente do ambiente ou latitude em que os mesmos ocorrem. E o caso de $C$. affinis, a espécie com maior distribuição geográficas do gênero, ocorrendo desde a Bahia até o Paraguai (Mamede, 1990a). Esta espécie raramente apresenta individuos portadores de flores casmógamas, sendo muito mais freqüente a ocorrência de espécimes exclusivamente cleistogâmicas. Por outro lado, fatores ambientais também parecem estar envolvidos no processo, uma vez que em condições de seca é mais freqüente a ocorrência de indivíduos portadores de flores cleistogâmicas. 0 que se observa freqüentemente no gênero é que indivíduos jovens ou ramos novos produzem exclusivamente e em grande quantidade flores cleistógamas. $\mathbf{O}$ aparecimento das flores casmógamas ocorre geralmente após a produção de frutos pelas flores cleistógamas.

0 valor adaptativo das flores cleistógamas em Camarea é evidente quando considera-se a pouca duração da porção aérea nas espécies do gênero, pois as mesmas asseguram a produção de sementes mesmo na ausência de polinizadores que promovam a fecundação cruzada entre as flores casmógamas.

Raramente os três carpelos (ou quatro em C. axillaris) das flores casmógamas de Camarea desenvolvem samarideos sendo freqüente o aborto de um dos lóculos, ou mais raramente de dois. Contrariamente, o ovário bicarpelar das flores cleistogâmicas origina sempre frutos constituídos de dois samarideos. Estes são morfologicamente idênticos aos originados de flores casmógamas, porém menores, e desenvolvem sementes e embriōes, exceção feita apenas a $C$. ericoides na qual não foram observados, até o momento, frutos originados das flores 
cleistógamas. Isto poderia ser explicado pelo mecanismo de auto-fecundação nas flores cleistógamas ser mais eficiente e garantido do que a fecundação cruzada das flores casmógamas, que depende da presença de agentes polizadores eficazes. Yaname \& Nakasone (1961) verificaram que em flores auto-fecundadas de Malpighia glabra L., a produção de frutos aumenta significativamente em relação a flores com fecundação cruzada. $\mathrm{O}$ mecanismo bizarro de auto- fecundação documentado por Anderson (1980) em Gaudichaudia spp. e Janusia guaranitica não foi observado em Camarea affins. A formação de saco embrionário nos óvulos de flores cleistógamas reforça a idéia de auto-fecundação como mecanismo de reprodução nessas flores. Porém, a suposição de que possa ocorrer apomixia nas flores cleistógamas de Camarea, especialmente no híbrido (Mamede, 1990b) não deve ser de todo descartada.

A ocorrência freqüente de carpelos abortados nas flores casmógamas de Camarea poderia ser explicada talvez pelo fato do tubo polinico não atingir um dos lóculos do ovário, uma vez que o estilete único das Camarea apresenta comunicação com um dos carpelos apenas. Uma das evidências que poderiam reforçar esta idéia é o fato de gêneros que apresentam três estiletes livres (como Banisteriopsis, Heteropteris, Peixotoa) desenvolverem frutos com três samarideos.

As alas dos samarideos de Camarea não atuam na disseminação dos diásporos pois são muito pequenas em relação ao núcleo seminífero. Pereira (1953) refere que os frutos muricados de Camarea aderem-se aos pêlos dos animais, dando-se assim a dispersão dos diásporos. No entanto, foram observados frutos de Camarea affinis caídos no solo proximo á planta-mãe, o que indica que talvez a disseminação passiva ocorra mais freqüentemente.

\section{Agradecimentos}

A autora gostaria de expressar seus agradecimentos à Dra Ana Maria Giulietti pela orientação; à Dra Margarida Venturelli (in memoriam) pelas sugestões e análise crítica deste trabalho: à Carmem Z. Fidalgo e Cibele B. Toledo pela cobertura a nanquim das ilustrações.

\section{Referências Bibliográficas}

ANDERSON, C. 1982. A monograph of the genus Peixotoa (Malpighiaceae). Contr. Univ. Mich. Herb. 15:1-92.

ANDERSON, WR. 1980. Cryptic self-fertilization in tre Malpighiaceae. Science 207:892-3

CONN, H.J., M.A. DARROW \& V.M. EMMEL. 1960. Staining procedures. Baaltimore, The Williams and Wilkins. 289p. 
GATES, B. 1982. Banisteriopsis, Diplopterys (Malpighiaceae). Flora Neotropica 30:1-237.

HAUMAN-MERCK, L. 1913. Observations sur la pollination d'une Malpighiacée. du genre Stigmaphyllon. Recl. Inst. bot Leo Errera 9:21-7

JUSSIEU, A. de 1843. Monographie de la familie des Malpighiacées. Archs. Mus. natn. Hist., Paris, 3:5-151, 255-616.

LORD, E.M. 1981. Cleistogamy: a tool for the study of floral morphogeneses function and evolution. Bot. Rev. 47(4):421-49.

LORENZO, E. 1981. Sobre la inflorescencia, morfologia floral y embriologia de Janusia guaranitica, (Malpighiaceae). Kurtziana 14:101-24.

MAMEDE, M.C.H. 1988. Revisão do gênero Camarea Saint-Hilaire (Malpighiaceae). São Paulo (Univ. de São Paulo, Tese de Doutorado). 293p.

MAMEDE, M.C.H. 1990a. Revisão do gênero Camarea Saint-Hilaire (Malpighiaceae). Hoehnea 17(1):1-34.

MAMEDE, M.C.H. 1990b. Observações sobre a ocorrência de prováveis hibridos entre Camarea affinis St.-Hil. e Camarea hirsuta St.-Hil. (Malpighiaceae). Hoehnea 17(1):35-46.

PEREIRA, E. 1953. Contribuição ao conhecimento da família Malpighiaceae. Archos. Serv. flor. Bras. 7:11-70.

RITZEROW, H. 1908. :Über Bau und Befruchtung kleistogamer Blüten. Flora, Regensburg, 98: 163-212.

SASS, J.S. 1951. Botanicial microtechnique. 2ed. Iowa, Iowa State College Press. 228p.

SAZIMA, M. \& I. SAZIMA. 1987. Malpighiaceae sem elaióforos e sua polinização por abelhas coletoras de óleos. In: Congresso Nacional de Botânica, 38, São Paulo, 1987. Resumos. São Paulo, Sociedade Brasileira de Botânica. p 243.

SIMPSON, B.B. \& J.L. NEFF. 1981. Floral rewards: alternatives to pollen and nectar. Ann. Mo. Bot. Gdn. 68:301-22.

SINGH, B. 1959. Studies in the family Malpighiaceae. I. Morphology of Thryallis glauca Kuntze. Hort. Adv. Saharanpur, 3:1-19.

SOARES, A.A. 1979 Contribuição ao estudo das sépalas de Bunchosia glandulifera (Jack) HBK (Malpighiaceae) e microscopia dos respectivos grãos de pólen. Anais $30^{\circ}$ Congresso Nacional de Botânica, Campo Grande, p. 23-6.

UPHOF, J.C. 1938. Cleistogamic flowers. Bot. Rev. 4(1):21-49.

VOGEL, S. 1974. ölblumen and ölsammelnde Bienen. Akad. Wiss. Match.Naturwiss. Kl. Trop. Pflanzenwelt 7:1-267.

YAMANE, G. M. \& H.Y. NAKASONE. 1961. Pollination and fruit set of acerola (Malpighia glabra L.) in Hawaii. Proc. Am. Soc. hort. Sci. 78:141-8. 